\title{
A review of flash glucose monitoring in type 2 diabetes
}

\author{
Marcio Krakauer ${ }^{1 *}$, Jose Fernando Botero², Fernando J. Lavalle-González ${ }^{3}$, Adrian Proietti ${ }^{4}$ and \\ Douglas Eugenio Barbieri ${ }^{5}$
}

\begin{abstract}
Background: Continuous glucose monitoring systems are increasingly being adopted as an alternative to self-monitoring of blood glucose (SMBG) by persons with diabetes mellitus receiving insulin therapy.

Main body: The FreeStyle Libre flash glucose monitoring system (Abbott Diabetes Care, Witney, United Kingdom) consists of a factory-calibrated sensor worn on the back of the arm which measures glucose levels in the interstitial fluid every minute and stores the reading automatically every $15 \mathrm{~min}$. Swiping the reader device over the sensor retrieves stored data and displays current interstitial glucose levels, a glucose trend arrow, and a graph of glucose readings over the preceding $8 \mathrm{~h}$. In patients with type 2 diabetes (T2D) receiving insulin therapy, pivotal efficacy data were provided by the 6-month REPLACE randomized controlled trial (RCT) and 6-month extension study. Compared to $S M B G$, the flash system significantly reduced the time spent in hypoglycemia and frequency of hypoglycemic events, although no significant change was observed in glycosylated hemoglobin ( $\mathrm{HbA1c}$ ) levels. Subsequent RCTs and real-world chart review studies have since shown that flash glucose monitoring significantly reduces HbA1c from baseline. Real-world studies in both type 1 diabetes or T2D populations also showed that flash glucose monitoring improved glycemic control. Higher (versus lower) scanning frequency was associated with significantly greater reductions in HbA1c and significant improvements in other measures such as time spent in hypoglycemia, time spent in hyperglycemia, and time in range. Additional benefits associated with flash glucose monitoring versus SMBG include reductions in acute diabetes events, all-cause hospitalizations and hospitalized ketoacidosis episodes; improved wellbeing and decreased disease burden; and greater treatment satisfaction.
\end{abstract}

Conclusion: T2D patients who use flash glucose monitoring might expect to achieve significant improvement in $\mathrm{HbA1C}$ and glycemic parameters and several associated benefits.

Keywords: Flash glucose sensing, Intermittent-scanned continuous interstitial glucose monitoring, Type 2 diabetes

\section{Background}

Self-monitoring of blood glucose (SMBG) is a wellestablished approach for daily management of glycemic control in persons with diabetes mellitus, including those with type 2 diabetes (T2D) [1, 2]. In recent years,

\footnotetext{
*Correspondence: marcio@nidomater.com.br

${ }^{1}$ Department of Technology (Coordinator) SBD-Brazilian Diabetes Society, Science Valley Research Center, Liga de Diabetes, ABC Medical School, Avenida 12 de Outubro 286, Santo André, SP CEP 09030-640, Brazil

Full list of author information is available at the end of the article
}

continuous glucose monitoring (CGM) systems have increasingly been adopted as an alternative or adjunct to SMBG by patients receiving insulin therapy $[3,4]$.

The FreeStyle Libre ${ }^{\mathrm{TM}}$ flash glucose monitoring system (Abbott Diabetes Care, Witney, United Kingdom) consists of a sensor which is applied to the back of the upper arm and inserted below the skin [5]. The sensor measures glucose levels in the interstitial fluid every minute and stores glucose data automatically every $15 \mathrm{~min}$. Each sensor lasts up to 14 days. A dedicated reader device or smartphone with near-field communication capability

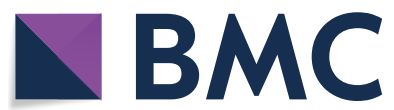

(c) The Author(s) 2021. This article is licensed under a Creative Commons Attribution 4.0 International License, which permits use, sharing, adaptation, distribution and reproduction in any medium or format, as long as you give appropriate credit to the original author(s) and the source, provide a link to the Creative Commons licence, and indicate if changes were made. The images or other third party material in this article are included in the article's Creative Commons licence, unless indicated otherwise in a credit line to the material. If material is not included in the article's Creative Commons licence and your intended use is not permitted by statutory regulation or exceeds the permitted use, you will need to obtain permission directly from the copyright holder. To view a copy of this licence, visit http://creativeco mmons.org/licenses/by/4.0/. The Creative Commons Public Domain Dedication waiver (http://creativecommons.org/publicdomain/ zero/1.0/) applies to the data made available in this article, unless otherwise stated in a credit line to the data. 
can be used at any time to scan the sensor to retrieve stored data. The device monitor displays the current glucose level, a trend arrow showing the direction in which glucose levels are heading, and a graph of glucose readings over the preceding $8 \mathrm{~h}$ (Fig. 1) [6].

The FreeStyle Libre system was approved in Europe in 2014 and, subsequently, in the United States (US) for professional use in 2016 and for personal use in 2017. The professional model uses 'blinded' sensors which patients bring into their physician's office at regular intervals to have the readings downloaded. The reader is owned and maintained by the attending healthcare professional. A single reader can be used to read multiple patient sensors. The personal version uses 'unblinded' sensors. Patients own the reader device (or use an app on a smartphone) and can scan the sensor at any time for real-time glucose readings [7].

This review examines evidence for the flash glucose monitoring system in patients with T2D, although several real-world studies had mixed type 1 diabetes (T1D) and T2D populations.

\section{Search strategy}

To identify clinical trials of the flash glucose monitoring system, searches were conducted of PubMed and Google Scholar from inception to 30 June 2020 using the search terms flash glucose monitoring; continuous and/

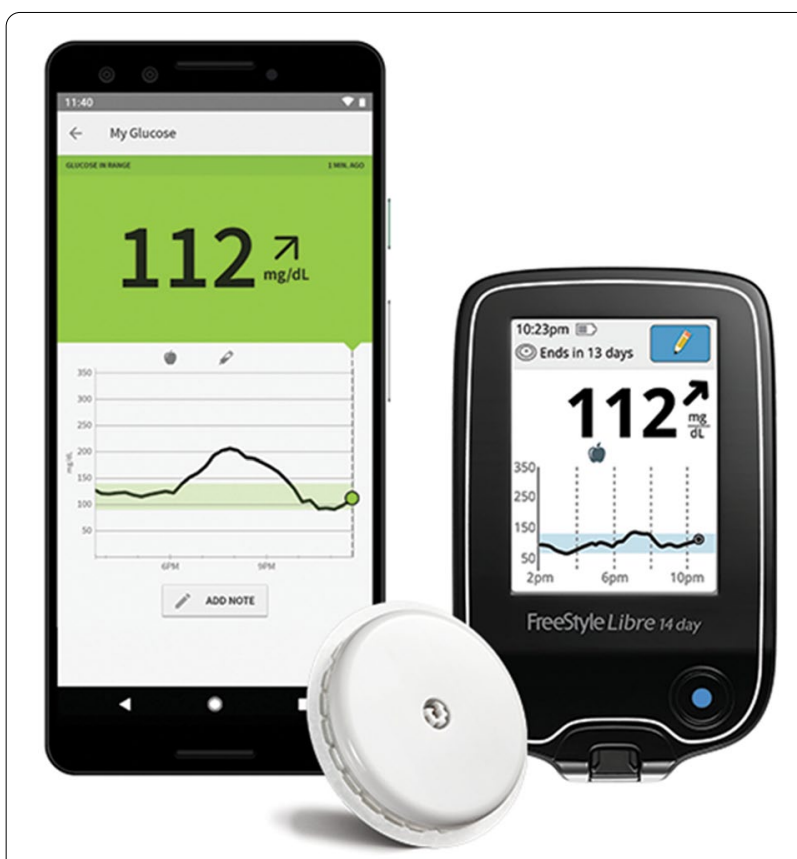

Fig. 1 FreeStyle Libre flash glucose monitoring system (Abbott Diabetes Care, Witney, United Kingdom): sensor, reader device and its display [6] or intermittent glucose monitoring; and FreeStyle Libre system. No language restrictions were applied. Reference lists of retrieved papers were hand-searched for additional clinical studies and other articles of interest. Relevant abstracts presented at the American Diabetes Association Congress in June 2020 were also considered for inclusion.

\section{Key evidence of flash glucose monitoring technology in type 2 diabetes REPLACE study}

The REPLACE open-label randomized controlled trial (RCT) of adults with T2D, which compared the efficacy and safety of flash glucose monitoring $(n=149)$ with SMBG $(\mathrm{n}=75)$, provided key supporting evidence for use of the technology in this setting [8]. The study aimed to assess the effect of flash glucose monitoring on glycemic control in patients receiving intensive insulin therapy or continuous subcutaneous insulin infusion. Although no significant difference was observed between flash technology and SMBG in the primary outcome measure of change in HbAlc at 6 months (mean -0.29 vs. $-0.31 \%$, respectively), prespecified subgroup analyses demonstrated several benefits (Table 1). The 6-month HbA1c level was significantly reduced in patients aged $<65$ years using the flash system compared with SMBG (mean -0.53 vs. $-0.20 \%$; $P=0.030$ ) although, for reasons not yet clear, the trend was reversed in patients aged $\geq 65$ years (mean -0.05 vs. $-0.49 \% ; P=0.008$ ). The authors hypothesized that "the benefit for older intervention participants of being able to visualize actual or potential hypoglycemic risk prompted a more cautious approach to therapy adjustments in this vulnerable group, prioritizing hypoglycemia reduction over a more indiscriminate approach to glucose control". Other glycemic measures significantly reduced with flash glucose monitoring compared with SMBG were time spent in hypoglycemia, frequency of hypoglycemic events and area under the concentrationtime curve (AUC) for glucose, with a reduction in each of these measures in inverse proportion to the glucose level (Table 1). SMBG frequency from baseline to study end was decreased in flash glucose monitoring participants from a mean \pm standard deviation (SD) of $3.8 \pm 1.4$ to $0.3 \pm 0.7$ tests/day. Treatment satisfaction, as assessed by the Diabetes Treatment Satisfaction Questionnaire, was higher in the flash glucose monitoring group compared with the SMBG group (mean \pm SE $13.1 \pm 0.50$ vs. $9.0 \pm 0.72 ; P<0.0001$ ). No serious adverse events (SAEs) or severe hypoglycemic events were reported in association with the device. Nine sensor adhesive reactions in six participants were described, with intensity reported as severe $(n=2)$, moderate $(n=6)$, or mild $(n=1)$. All 
Table 1 Efficacy of the flash glucose monitoring system versus self-monitoring of blood glucose in the REPLACE open-label randomized controlled trial and extension study in patients with type 2 diabetes mellitus

\begin{tabular}{|c|c|c|c|}
\hline \multirow{2}{*}{$\begin{array}{l}\text { Randomized controlled trial } \\
\text { Overall population ( } 6 \text { months) }\end{array}$} & \multicolumn{2}{|l|}{ Outcome (FGMS vs. SMBG) $[N=149$ vs. $N=75]$} & \multirow{2}{*}{$\begin{array}{l}P \text { value } \\
P=0.8222\end{array}$} \\
\hline & Mean change from baseline in $\mathrm{HbA} 1 \mathrm{c}$ : & $-0.29 \pm 0.07$ vs. $-0.31 \pm 0.09 \%$ & \\
\hline \multicolumn{4}{|l|}{ Subgroup analyses (6 months) } \\
\hline \multicolumn{4}{|l|}{ Age } \\
\hline$<65$ years & \multirow[t]{2}{*}{ Mean change from baseline in $\mathrm{HbA1c}$ : } & $-0.53 \pm 0.09$ vs. $-0.20 \pm 0.12 \%$ & $P=0.0301$ \\
\hline$\geq 65$ years & & $-0.05 \pm 0.10$ vs. $-0.49 \pm 0.13 \%$ & $P=0.0081$ \\
\hline \multicolumn{4}{|c|}{ Time spent in hypoglycemia [h/day]: mean change from baseline } \\
\hline Glucose $<70 \mathrm{mg} / \mathrm{dL}$ & \multirow[t]{3}{*}{ Between-group difference: } & $-43 \%[$ mean $\pm S E-0.47 \pm 0.13]$ & $P=0.0006$ \\
\hline Glucose $<55 \mathrm{mg} / \mathrm{dL}$ & & $-53 \%[-0.22 \pm 0.07]$ & $P=0.0014$ \\
\hline Glucose $<45$ mg/dL & & $-64 \%[-0.14 \pm 0.04]$ & $P=0.0013$ \\
\hline \multicolumn{4}{|c|}{ Frequency of hypoglycemic events [per day]: mean change from baseline } \\
\hline Glucose $<70 \mathrm{mg} / \mathrm{dL}$ & \multirow[t]{4}{*}{ Between-group difference: } & $-28 \%[$ mean $\pm S E-0.16 \pm 0.07]$ & $P=0.0164$ \\
\hline Glucose $<55 \mathrm{mg} / \mathrm{dL}$ & & $-44 \%[-0.12 \pm 0.04]$ & $P=0.0017$ \\
\hline Glucose $<45 \mathrm{mg} / \mathrm{dL}$ & & $-49 \%[-0.06 \pm 0.02]$ & $P=0.0098$ \\
\hline \multicolumn{3}{|l|}{$\mathrm{AUC}[\mathrm{h} / \mathrm{day} \times \mathrm{mg} / \mathrm{dL}]$} & \\
\hline Glucose $<70 \mathrm{mg} / \mathrm{dL}$ & \multirow[t]{3}{*}{ Between-group difference: } & $-51 \%[$ mean $\pm S E-7.80 \pm 2.20]$ & $P=0.0005$ \\
\hline Glucose $<55$ mg/dL & & $-60 \%[-2.51 \pm 0.76]$ & $P=0.0012$ \\
\hline Glucose $<45 \mathrm{mg} / \mathrm{dL}$ & & $-67 \%[-0.70 \pm 0.22]$ & $P=0.0015$ \\
\hline Extension phase & \multicolumn{2}{|l|}{ Outcome (FGMS vs. baseline) $[\mathrm{N}=139]$} & \\
\hline \multicolumn{4}{|l|}{ Subgroup analyses (12 months) } \\
\hline \multicolumn{4}{|c|}{ Time spent in hypoglycemia [h/day] } \\
\hline Glucose $<70 \mathrm{mg} / \mathrm{dL}$ & \multirow{3}{*}{$\begin{array}{l}\text { Mean change from baseline (start of treatment } \\
\text { phase): }\end{array}$} & $-50 \%[$ mean $\pm S D-0.70 \pm 1.85]$ & $P=0.0002$ \\
\hline Glucose $<55 \mathrm{mg} / \mathrm{dL}$ & & $-62 \%[-0.40 \pm 1.09]$ & $P=0.0002$ \\
\hline Glucose $<45 \mathrm{mg} / \mathrm{dL}$ & & $-67 \%[-0.23 \pm 0.73]$ & $P=0.0013$ \\
\hline \multicolumn{4}{|c|}{ Frequency of hypoglycemic events [per day] } \\
\hline Glucose $<70 \mathrm{mg} / \mathrm{dL}$ & \multirow{3}{*}{$\begin{array}{l}\text { Mean change from baseline (start of treatment } \\
\text { phase): }\end{array}$} & $-41 \%[$ mean $\pm S D-0.27 \pm 0.67]$ & $P<0.0001$ \\
\hline Glucose $<55 \mathrm{mg} / \mathrm{dL}$ & & $-56 \%[-0.20 \pm 0.49]$ & $P<0.0001$ \\
\hline Glucose $<45 \mathrm{mg} / \mathrm{dL}$ & & $-62 \%[-0.13 \pm 0.35]$ & $P=0.0002$ \\
\hline \multicolumn{4}{|l|}{$\mathrm{AUC}[\mathrm{h} / \mathrm{day} \times \mathrm{mg} / \mathrm{dL}]$} \\
\hline Glucose $<70 \mathrm{mg} / \mathrm{dL}$ & \multirow{3}{*}{$\begin{array}{l}\text { Mean change from baseline (start of treatment } \\
\text { phase): }\end{array}$} & $-58 \%($ mean $\pm S D-12.73 \pm 34.53]$ & $P=0.0002$ \\
\hline Glucose $<55 \mathrm{mg} / \mathrm{dL}$ & & $-65 \%[-4.28 \pm 12.76]$ & $P=0.0007$ \\
\hline Glucose $<45 \mathrm{mg} / \mathrm{dL}$ & & $-69 \%[-1.12 \pm 3.67]$ & $P=0.0021$ \\
\hline
\end{tabular}

Data from $[8,9]$

BG levels are presented as $\mathrm{mg} / \mathrm{dL}$, which can be converted to $\mathrm{mmol} / \mathrm{L}$ by multiplying values by 0.05551

$A U C$ area under the concentration-time curve, FGMS flash glucose monitoring system, $H b A 1 c$ glycosylated haemoglobin, SMBG self-monitoring of blood glucose

reactions resolved with treatment, using mainly topical preparations.

\section{REPLACE extension study}

A total of 139 participants in the flash glucose monitoring group of the REPLACE RCT completed the 6-month treatment phase and continued into a 6-month openaccess phase [9]. The mean changes from baseline (start of treatment period) in glycemic parameters measured at 12 months paralleled those measured at 6 months. Significant reductions in sensor measures of time spent in hypoglycemia, number of hypoglycemic events, and glucose AUC were observed for open-access participants at 12 months post-baseline compared with baseline, and the magnitude of change increased as glucose cut-off points decreased (Table 1).

Time in range (sensor glucose $70-180 \mathrm{mg} / \mathrm{dL}$ ) remained unchanged between baseline and 12 months post-baseline $(14.0 \pm 4.4$ vs. $14.1 \pm 4.0 \mathrm{~h})$. Mean \pm SD frequency of SMBG decreased from $3.9 \pm 1.2$ tests/day at baseline to $0.2 \pm 0.6$ tests/day at 12 months post-baseline. During 12 months' use of the flash glucose monitoring device there were no reports of diabetic ketoacidosis or a state of hyperosmolar hyperglycemia. As in the parent 
study, no SAEs were attributable to the device. Sixteen device-related adverse events (sensor adhesive or site reactions) were reported in nine participants, which were classified as severe $(n=4)$, moderate $(n=9)$ or mild $(n=3)$. All events resolved after treatment with mainly topical preparations.

Collectively, the 6-month REPLACE RCT and followon 6-month open-access study showed that, in individuals with T2D managed by intensive insulin therapy, the flash glucose monitoring system reduces hypoglycemia and is a safe alternative to SMBG. In the initial 6-month phase, the mean $\pm S D$ number of scans/day recorded by the flash glucose monitoring device was $8.3 \pm 4.4$ (median 6.8), which was double the frequency of blood glucose testing (median 3.8 \pm 1.9 tests/day) [8]. Average sensor-scanning frequency during the extension phase was 7.1 \pm 3.5 times/day (median 5.7) [9].

\section{Other randomized clinical trials}

A pilot RCT compared the effect on glycemia of intermittent wearing of the professional flash glucose monitoring sensor with SMBG in insulin-treated T2D patients with a HbA1c level between 7.5 and $12.0 \%$ [10]. Patients performed SMBG $(n=52$, control group A), or SMBG plus flash sensor worn for two 14-day periods during 4.5 months $(n=46$, intervention group B), or SMBG plus flash sensor worn for four 14-day periods during 7 months $(n=50$, intervention group $C)$. No significant changes were observed within group $C$ for sensor-derived time in range $(70-180 \mathrm{mg} / \mathrm{dL})$ from baseline to penultimate sensor wear (days 172-187; primary endpoint), with mean $\pm S D$ values of $15.0 \pm 5.0$ and $14.1 \pm 4.7 \mathrm{~h} /$ day, respectively, or for the difference versus the control group at study end (days 215-230). In group C, HbA1c was reduced significantly during the study period by a mean \pm SD of $0.44 \% \pm 0.81 \%(P=0.0003)$. At study end, HbA1c was significantly reduced in group $C$ compared with the control group by an adjusted mean $\pm \mathrm{SE}$ of $0.48 \% \pm 0.16 \%(P=0.004)$. In contrast, there was no significant difference in HbA1c between group B and control group at day $144(P=0.133)$. The authors concluded that flash glucose monitoring in T2D patients can "introduce clinically meaningful changes in HbA1c".

An open-label RCT compared the effect of 10-week flash glucose monitoring $(n=53)$ or SMBG $(n=48)$ on glycemic control in patients with $\mathrm{T} 2 \mathrm{D}$ receiving multiple daily insulin injections [11]. HbA1c was significantly reduced in the flash device group compared with SMBG, with mean changes from baseline of $-0.82 \%$ and $-0.33 \%$, respectively $(P=0.005)$. Non-prespecified post hoc analyses showed that higher proportions of patients in the flash device group, compared with the SMBG group, had HbA1c reductions of $\geq 0.5 \%$ (68.6 vs. $30.2 \%$;
$P<0.001)$, or of $\geq 1.0 \%$ (39.2 vs. $18.6 \% ; P=0.0023)$. No significant differences were found in the mean \pm SD perceived frequency of hypoglycemic episodes: $1.41 \pm 1.29$ vs. $0.75 \pm 1.57$, respectively $(P=0.066)$. There was a trend towards higher treatment satisfaction in the flash device group, with a mean Diabetes Treatment Satisfaction Questionnaire change version score of $2.47 \pm 0.77$ compared with $2.18 \pm 0.83$ in the standard care group $(P=0.053)$. Patients found flash glucose monitoring to be significantly more flexible than SMBG $(2.28 \pm 1.28$ vs. $1.61 \pm 1.59, P=0.019)$, and more would recommend it to their counterparts $(2.61 \pm 0.86$ vs. $2.19 \pm 1.04, P=0.023)$.

\section{Real-world observational studies}

Retrospective real-world chart review studies from three European countries examined the effectiveness of flash glucose monitoring on HbA1c in adults with T2D managed by basal bolus insulin therapy [12]. Medical records from centers in Austria $(n=92)$, France $(n=88)$ and Germany $(n=183)$ were evaluated prior to, and following, use of the device for 90 days. Mean \pm SD changes in HbA1c $\quad$ were $-0.9 \% \pm 0.8 \% \quad(P<0.0001),-0.8 \% \pm 1.1 \%$ $(P<0.0001)$ and $-0.9 \% \pm 1.1 \%(P<0.0001)$, respectively. In a combined analysis of the three studies, the overall effect size was $-0.9 \%(P<0.0001$ vs. baseline $)$. There was no significant heterogeneity between studies performed in each country $(P=0.711)$. No significant differences were recorded for changes in HbA1c according to age group, gender, body mass index, or duration of insulin use.

A real-world retrospective, observational study which analyzed data from the US electronic health record database IBM Explorys showed that de novo use of flash glucose monitoring significantly reduced HbA1c in T2D patients $(n=1084)$ not using bolus insulin [13]. Mean HbA1c levels decreased from $10.1 \%$ at baseline to $8.6 \%$ within 60-300 days of the flash glucose monitoring prescription $(P<0.001)$. Similarly, another real-world retrospective study which analyzed claims data by the Decision Resources Group, a commercial medical and pharmacy claims database, showed a significant reduction in HbA1c levels in T2D patients on long-acting insulin or non-insulin therapy after 6-month and 12-month use of flash glucose monitoring [14]. Mean HbA1c was reduced by $0.8 \%$ (from 8.5 to $7.7 \%$ ) in the 6 -month T2D cohort $(\mathrm{n}=774)$, and by $0.6 \%$ (from 8.5 to $7.9 \%$ ) in the 12-month T2D cohort $(\mathrm{n}=207)$ (both $P<0.0001)$.

\section{Evidence interpretation}

The reasons for discordance between the REPLACE trial [8] and subsequent RCTs [10,11] and real-world studies [12-14] with respect to the effects of flash glucose monitoring on HbA1c are unknown, although the 
weight of evidence supports a reduction in HbA1c. It is important to highlight that patient inclusion criteria differed among studies with some patient populations using intensive insulin therapy and others not. The 12-month General Practice Optimising Structured MOnitoring To achieve Improved Clinical Outcomes (GP-OSMOTIC) trial, which compared professional-mode (masked) flash glucose monitoring with usual care (non-insulin glucose-lowering drugs, insulin, or both) in 299 adults with T2D in primary care, reported a significant reduction in mean HbA1c with flash monitoring at 6 months $(-0.5 \%$; $P=0.0001)$ but not at 12 months $(-0.3 \% ; P=0.059)$, although the mean percentage of time spent in target glucose range at 12 months was $7.9 \%$ higher with flash monitoring than usual care $(P=0.0060)$ [15]. An interesting critique of the GP-OSMOTIC study, which drew attention to issues of adherence $(78 \%$ at 9 months in the flash glucose monitoring group) and the absence of glucose monitoring data discussion with $43 \%$ of the intervention sample, suggested that unmasked flash glucose monitoring (i.e. a patient-based personal use system) "could be a further step from an expert-only approach to shared decision-making" [16].

Two recent real-world retrospective, observational analyses of the MarketScan database, which contains insurance billing claims for inpatient, outpatient, and pharmacy expenses, have shown benefits for flash glucose monitoring beyond glycemic control. In T2D patients not using bolus insulin $(\mathrm{n}=7167)$, de novo flash glucose monitoring use (purchased between Q4 of 2017 and Q4 of 2018) significantly reduced inpatient and outpatient emergency acute diabetes events from 0.071 to 0.052 events/patient-year (hazard ratio [HR]: 0.70; 95\% CI $0.57-0.85 ; P<0.001)$, and all-cause hospitalization from 0.180 to 0.161 events/patient-year (HR: 0.87; 95\% CI $0.78-0.98 ; P=0.025)$ [17]. In T2D patients receiving fast- or short-acting insulin, flash glucose monitoring use (purchased between Q4 of 2017 and Q2 of 2018) significantly reduced acute diabetes events from 0.158 to 0.077 events/patient-year (HR: 0.49; 95\% CI 0.34-0.69; $P<0.001)$ and all-cause hospitalization from 0.345 to 0.247 events/patient-year (HR: 0.72 ; 95\% CI 0.58-0.88; $P=0.002)[18]$.

\section{Real-world observational studies in mixed populations of T1D and T2D}

Real-world observational studies from several world regions have assessed the impact of flash glucose monitoring in often large groups of patients with T1D or T2D. The studies are described briefly and the results are presented by outcome, namely the effect of flash glucose monitoring on $\mathrm{HbA1c}$, measures of hypoglycemia and hyperglycemia, and other effectiveness parameters.
A retrospective nationwide study of reimbursement claims from a French database assessed ketoacidosis rates in T1D $(n=33,203)$ and T2D $(n=40,955)$ patients who initiated flash glucose monitoring use during a 5-month study period in 2017 [19].

Four studies assessed the benefits of flash glucose monitoring mainly on HbA1c. A Dutch prospective nationwide registry study which analyzed data from 1365 participants with T1D (77.2\%), T2D (16.4\%), Latent Autoimmune Diabetes in Adults (4.6\%) or maturity-onset diabetes of the young (0.5\%) examined the effect of flash glucose monitoring on $\mathrm{HbA1c}$, disease burden and wellbeing [12]. A cohort study using data from the Swedish National Diabetes Register (January 2014-June 2019) assessed the effectiveness of the FreeStyle Libre system on HbA1c reduction [21]. A meta-analysis of 29 clinical trials and real-world studies, of which 25 reported longitudinal HbA1c data in 1723 participants with T1D or T2D using the FreeStyle Libre system, examined the impact of flash glucose monitoring on HbA1c [22] A small study from Israel assessed the impact of flash glucose monitoring on HbA1c in T2D $(n=25)$ and T1D $(\mathrm{n}=6)$ patients [23].

Other studies assessed the impact of increased scanning frequency on glycemic measures. A real-world European analysis examined deidentified data from more than 50,000 users worldwide of the FreeStyle Libre system who had performed more than 60 million scans over a 20-month period [24]. To assess the role of flash glucose monitoring in early and late changes of glycemic markers under real-life conditions, a longitudinal study analyzed deidentified glucose results from 6802 flash monitors after stratification into high, medium and low-risk groups based on tertiles of time spent in hypoglycemia ( $\mathrm{min} /$ day $<70 \mathrm{mg} / \mathrm{dL}$ ) or hyperglycemia (h/day $>240 \mathrm{mg} / \mathrm{dL}$ ) [25]. Another large real-world study analyzed deidentified glucose and user scanning data (250 million glucose readings, 37.1 million glucose scans) collected over a 4-year period from Spanish users $(n=22,949)$ to determine the relationship between testing frequency and glycemic parameters [26]. An interesting study from Brazil analyzed glucose results captured from launch of the FreeStyle Libre flash glucose monitor in 2016 and compared them with global population data collected between September 2014 and December 2018 [27]. Data were analyzed from 688,640 readers and $7,329,052$ sensors worldwide, including 17,691 readers and 147,166 sensors from Brazil.

\section{Effect on HbA1c}

Four studies showed that flash glucose monitoring improved glycemic control, as assessed by HbA1c, compared with prior to its use (Table 2) [20-23]. In the 
Table 2 Effect of flash glucose monitoring use and scanning frequency on glycosylated hemoglobin (HBA1c) levels in real-world studies of patients with type 1 and type 2 diabetes

\begin{tabular}{|c|c|c|}
\hline Study (population) & Effect of: & $\mathrm{HbA} 1 \mathrm{c}(\%)$ \\
\hline $\begin{array}{l}\text { Fokkert et al. [20] } \\
\text { T1D, } n=1054 ; T 2 D, n=223 ; \text { Other, } n=88\end{array}$ & Before vs. after FGMS use on estimated $\mathrm{HbA} 1 \mathrm{c}$ & $\begin{array}{l}\text { At baseline: } 8.0 \% \text { ( } 95 \% \mathrm{Cl} 7.9-8.1) \\
\text { At } 6 \text { months: } 7.6 \%(95 \% \mathrm{Cl} 7.5-7.7) ; P<0.001 \text { vs. } \\
\text { baseline } \\
\text { At } 12 \text { months: } 7.6 \% \text { ( } 95 \% \mathrm{Cl} 7.6-7.7) ; P<0.001 \text { vs. } \\
\text { baseline }\end{array}$ \\
\hline $\begin{array}{l}\text { Eeg-Olofsson et al. [21] } \\
\text { T1D, } n=8316 ; T 2 D, n=538\end{array}$ & $\begin{array}{l}\text { Before vs. after FGMS use on HbA1c (method of } \\
\text { measurement not specified) }\end{array}$ & $\begin{array}{l}\text { T1D: } 8.1 \% \text { at baseline. Mean change }-0.33 \%(95 \% \\
\text { Cl }-0.36 \text { to }-0.31) ; P<0.0001 \\
\text { T2D: } 8.6 \% \text { at baseline. Mean change }-0.52 \%(95 \% \\
\text { Cl }-0.63 \text { to }-0.40) ; P<0.0001\end{array}$ \\
\hline $\begin{array}{l}\text { Evans et al. [22] } \\
\text { Meta-analysis of } 29 \text { studies; } n=1723 \text { with T1D } \\
\text { or T2D }\end{array}$ & FGMS use on laboratory $\mathrm{HbA1c}$ & $\begin{array}{l}\text { In adults at } 2-4 \text { months: mean change }-0.56 \% \\
\quad(95 \% \mathrm{Cl}-0.76 \text { to }-0.36) \\
\text { In children and adolescents at } 2-4 \text { months: mean } \\
\text { change }-0.54 \%(95 \% \mathrm{Cl}-0.84 \text { to }-0.23)\end{array}$ \\
\hline $\begin{array}{l}\text { Ish-Shalom et al. [23] } \\
\text { T1D, } n=6 ; T 2 D, n=25\end{array}$ & $\begin{array}{l}\text { FGMS use on } \mathrm{HbA1c} \text { (method of measurement } \\
\text { not specified) }\end{array}$ & $\begin{array}{l}\text { In patients with } \mathrm{HbA} 1 \mathrm{c} \geq 7.5 \% \\
\text { At } 8 \text { weeks: mean change }-1.33 \pm 0.29 \% \\
\quad P<0.0001 \\
\text { At } 24 \text { weeks: mean change }-1.21 \pm 0.42 \% \\
\quad P=0.009\end{array}$ \\
\hline $\begin{array}{l}\text { Dunn et al. [24] } \\
n>50,000\end{array}$ & $\uparrow$ Scanning frequency on estimated $\mathrm{HbA} 1 \mathrm{c}$ & $\begin{array}{l}\text { Highest ( } 48.1 \text { scans/day) vs. lowest ( } 4.4 \text { scans/day) } \\
\text { scan rate group: } \\
6.7 \% \text { ( } 95 \% \text { Cl 6.7-6.8) vs. 8.0\% ( } 95 \% \text { Cl 7.9-8.0; } \\
P<0.001\end{array}$ \\
\hline $\begin{array}{l}\text { Gomez-Peralta et al. [26] } \\
n=22,949\end{array}$ & $\uparrow$ Scanning frequency on estimated $\mathrm{HbA} 1 \mathrm{c}$ & $\begin{array}{l}\text { Highest ( } 39.6 \text { scans/day) vs. lowest ( } 3.9 \text { scans/day) } \\
\text { scan rate group: } \\
6.9 \%(95 \% \text { Cl 6.9-7.0) vs. 8.0\% ( } 95 \% \text { Cl 8.0-8.1); } \\
P<0.001\end{array}$ \\
\hline $\begin{array}{l}\text { Calliari et al. [27] } \\
\text { Brazil: } 17,691 \text { readers and 147,166 sensors } \\
\text { Worldwide: } 688,640 \text { readers and 7,329,052 } \\
\text { sensors }\end{array}$ & $\uparrow$ Scanning frequency on estimated $\mathrm{HbA} 1 \mathrm{c}$ & $\begin{array}{l}\text { Brazil: Highest (43.1 scans/day) vs. lowest ( } 3.6 \\
\text { scans/day) scan rate group: } \\
6.7 \% \text { ( } 95 \% \mathrm{Cl} 6.6-6.8) \text { vs. } 7.6 \% \text { ( } 95 \% \mathrm{Cl} 7.4-7.7) ; \\
\text { P<0.01 } \\
\text { Worldwide: Highest ( } 37.8 \text { scans/day) vs. lowest } \\
\text { (3.4 scans/day) scan rate group: } \\
6.7 \%(95 \% \mathrm{Cl} 6.7-6.7) \text { vs. } 8.1 \% \text { ( } 95 \% \mathrm{Cl} 8.1-8.2) \\
\quad P<0.01\end{array}$ \\
\hline
\end{tabular}

BG levels are presented as $\mathrm{mg} / \mathrm{dL}$, which can be converted to $\mathrm{mmol} / \mathrm{L}$ by multiplying values by 0.05551

$B G$ blood glucose, FGMS flash glucose monitoring system, HbA1c glycosylated haemoglobin, T1D type 1 diabetes, T2D type 2 diabetes

$\uparrow$ indicates increased

Dutch prospective registry study, estimated HbA1c decreased from $8.0 \%$ before use of flash glucose monitoring to $7.6 \%$ after 6 months of use $(P<0.001)$ and remained steady at $7.6 \%$ at 12 months $(P<0.001)$. The 12 -month difference in estimated HbAlc was more pronounced in patients with T2D $(\mathrm{n}=223)$ than T1D $(\mathrm{n}=1054)$ [20]. Swedish National Diabetes Register data also showed a significant decrease in HbA1c (method of measurement unspecified) before and after incident FreeStyle Libre use, with a mean change of $-0.33 \%$ for T1D patients $(\mathrm{n}=8,316)$ and $-0.52 \%$ for T2D patients ( $\mathrm{n}=538$ ) at 12 months (both $P<0.0001$ ) [21]. The metaanalysis of clinical trials and real-world studies of flash glucose monitoring indicated a mean change in laboratory $\mathrm{HbA} 1 \mathrm{c}$ of $-0.55 \%$ at $2-4$ months, with a negligible difference $(-0.56 \%$ and $-0.54 \%$, respectively) observed between adults $(\mathrm{n}=1023)$ and children and adolescents $(\mathrm{n}=447)$ [22]. Longitudinal analysis of studies involving adult subjects $(\mathrm{n}=1276)$ showed that laboratory HbA1c was reduced within the first 2 months of use, and that changes were sustained for up to 12 months [22], thus confirming a trend observed in a previous small study of flash glucose monitoring in patients with $\mathrm{HbA} 1 \mathrm{c} \geq 7.5 \%$, in which the majority of change from baseline in mean HbA1c (method of measurement unspecified) occurred by 8 weeks $(-1.33 \% ; P<0.0001)$ and was maintained at 24 weeks $(-1.21 \% ; P=0.009)$ [23].

Additional studies showed that people who scan more frequently tend to have lower HbA1c (Table 2) [24, $26,27]$. In the European real-world analysis, greater scanning frequency from 4.4 (lowest) to 48.1 (highest) scans/ 
day was associated with a reduction in estimated HbA1c from $8.0 \%$ to $6.7 \%(P<0.001)$ [24]. In the real-world study of Spanish users of the flash glucose monitoring device, estimated HbA1c was significantly lower in the highest (39.6 scans/day) versus lowest (3.9 scans/day) scan frequency group (6.9 vs. $8.0 \% ; P<0.001)$ [26]. Similarly, the Brazilian study found that, in line with worldwide data, increased scanning frequency in Brazil was associated with better glycemic control, as evidenced by a lower estimated HbA1c in the highest (43.1 scans/day) versus lowest (3.6 scans/day) scan rate groups (6.7 vs. 7.6\%; $P<0.01)$ [27].

\section{Effect on measures of hypoglycemia and hyperglycemia}

Results from four real-world studies showed that increased scanning frequency of the flash monitoring device was associated with benefits on glycemic measures apart from HbA1c (Table 3) [24-27].

In the European analysis, greater scanning frequency was inversely correlated with time spent in hypoglycemia and hyperglycemia. For blood glucose levels $<70 \mathrm{mg} /$ $\mathrm{dL},<56 \mathrm{mg} / \mathrm{dL}$ and $<45 \mathrm{mg} / \mathrm{dL}$, time in hypoglycemia was lower by $15 \%, 40 \%$ and $49 \%$, respectively (all $P<0.001)$ in the highest (48.1 scans/day) compared with the lowest (4.4 scans/day) scan rate group. Highest versus lowest scanning frequency was also associated with a $44 \%$ decrease $(P<0.001)$ in time spent in hyperglycemia and a $40 \%$ increase in time in range [24]. Six-month data from the real-world longitudinal study showed that, in the high-risk hypoglycemia group, flash glucose monitoring significantly $(P<0.0001)$ reduced the mean time spent in hypoglycemia (blood glucose $\leq 70 \mathrm{mg} / \mathrm{dL}$ ) from the first to last 14-day periods of the study, irrespective of scanning frequency (high, medium, or low). In the high-risk hyperglycemia group, flash glucose monitoring reduced the time spent in hyperglycemia (blood glucose $>240 \mathrm{mg} / \mathrm{dL}$ ) by $0.8 \mathrm{~h} /$ day in higher-frequency scanners $(P<0.0001)$, by $0.3 \mathrm{~h} /$ day in medium-frequency scanners $(P=0.02)$, and had no effect in low-frequency scanners from the first to last 14-day periods of the study [25].

In the real-world study of Spanish users of the flash glucose monitoring device, glucose parameters progressively improved as average scanning frequency increased from the lowest (3.9 scans/day) to highest (39.6 scans/day) scan rate group. Time in hypoglycemia for blood glucose thresholds of $<70 \mathrm{mg} / \mathrm{dL}$ and $\leq 54 \mathrm{mg} / \mathrm{dL}$, respectively, was decreased by $14 \%$ and $37 \%$ in the highest versus lowest scan rate group. Respective times in hypoglycemia for the highest and lowest scan rate groups were 85.3 and $99.2 \mathrm{~min} /$ day $(P<0.001)$ for blood glucose $<70 \mathrm{mg} /$ $\mathrm{dL}$; and $29.7 \mathrm{~min} /$ day and $46.8 \mathrm{~min} /$ day for blood glucose $\leq 54 \mathrm{mg} / \mathrm{dL}$. Time spent in hyperglycemia (blood glucose $>180 \mathrm{mg} / \mathrm{dL})$ was decreased by $37 \%(P<0.001)$, and time in range was increased by $36 \%(P<0.001)$ and in the highest versus lowest scan rate group [26]. A comparison of sensor data derived from flash glucose monitoring users in Brazil and worldwide showed significant $(P<0.01)$ improvements in time spent in hyperglycemia (blood glucose $>180 \mathrm{mg} / \mathrm{dL}$ ) associated with highest versus lowest scanning frequency: 43.1 and 3.6 scans/day, respectively, in Brazil; 37.8 and 3.4 scans/day, respectively, worldwide [27]. In both populations, greater scanning frequency also increased time in range (blood glucose 70-180 mg/dL) [27], a glycemic metric gaining international recognition as a useful and appropriate clinical target [28].

\section{Other effects}

The retrospective study analyzing reimbursement claims from a French database showed a marked reduction in ketoacidosis rates in patients who initiated flash glucose monitoring during a 5-month study period in 2017. The hospitalization rate for ketoacidosis (excluding incidence for coma) was reduced by $52 \%$ (from 5.5 to 2.6 per 100 patient-years) and by $47 \%$ (from 1.7 to 0.9 per 100 patient-years) in T1D and T2D patients, respectively [19].

In the Dutch prospective registry study, 12-month use of flash glucose monitoring significantly reduced the proportion of patients experiencing any hypoglycemic event from 93.5 to $91.0 \%$; the proportion of diabetes-related hospitalization from 13.7 to $4.7 \%$; and work absenteeism from 18.5 to $7.7 \%$ (all comparisons $P<0.05$ ). In addition, flash glucose monitoring improved 12-month well-being scores, with changes from baseline of 0.03 (95\% CI 0.010.05) in the EuroQol 5D tariff, 4.4 (95\% CI 2.1-6.7) in the EQ-visual analogue scale, and 3.3 (95\% CI 2.1-4.4) in the 12-Item Short Form Health Survey v2 mental component score [20].

\section{Conclusion}

Data on use of flash glucose monitoring in people with T2D are accumulating steadily. Although no significant changes in HbA1c levels were observed in the REPLACE trial which compared flash glucose monitoring with SMBG in adults with $\mathrm{T} 2 \mathrm{D}$ receiving intensive insulin therapy, additional RCTs and real-world chart review studies have since documented that flash glucose monitoring significantly reduces $\mathrm{HbA} 1 \mathrm{c}$ from baseline. Realworld studies of both populations of patients with T1D or T2D indicate that flash glucose monitoring is associated with less time spent in hypoglycemia or hyperglycemia, and greater time in target glucose range. Higher scanning frequency was associated with better glycemic metrics, particularly among patients at higher risk of hyperglycemia or hypoglycemia who spent significantly less time 


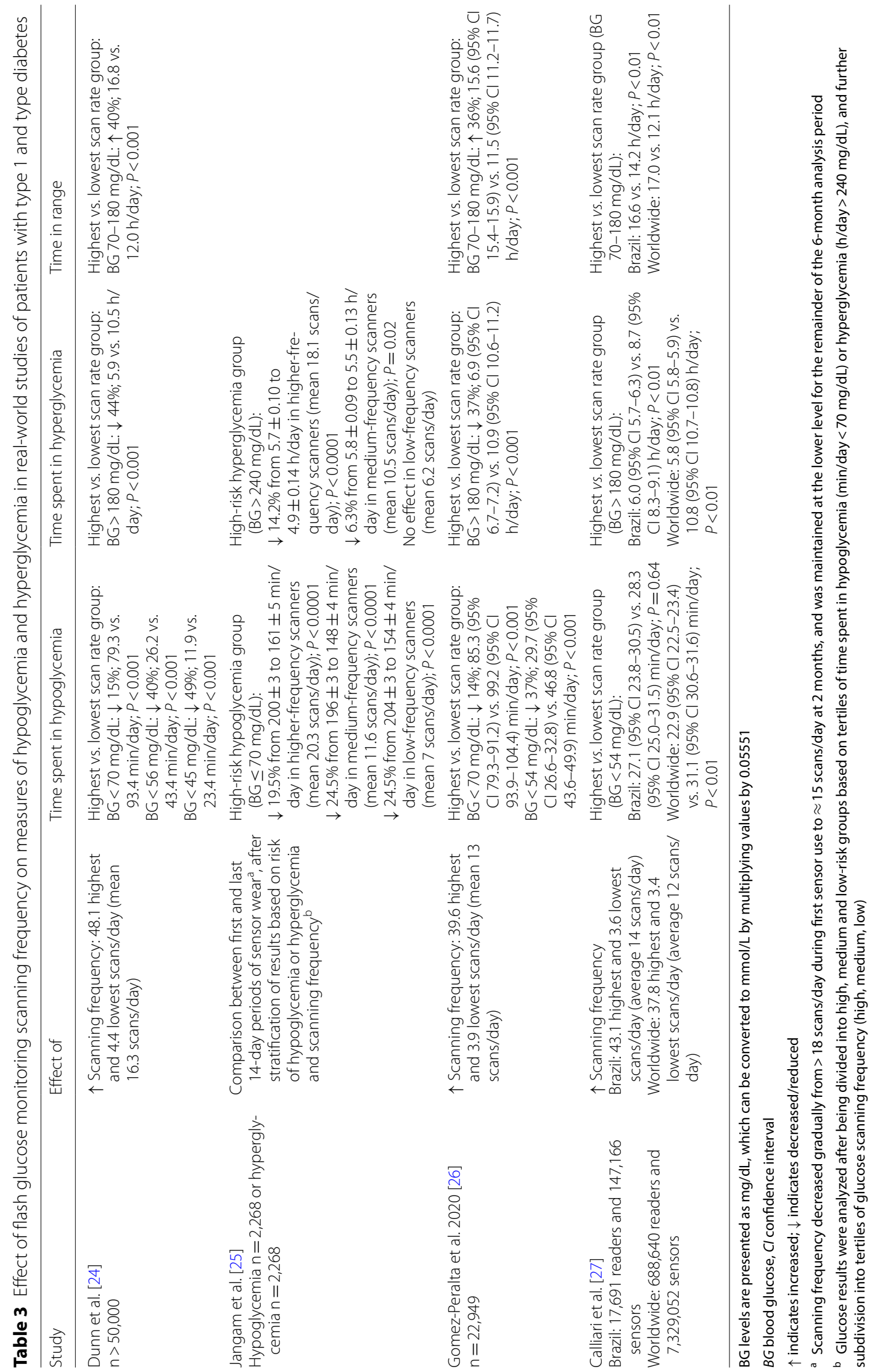


above or below target values. Other benefits reported with use of flash glucose monitoring include reductions in acute diabetes events and all-cause hospitalizations, reductions in hospitalized ketoacidosis episodes (except comas), improved well-being and decreased disease burden, and greater treatment satisfaction. Taken together, the evidence indicates that flash glucose monitoring is suitable and safe for use in T2D patients, especially those who could benefit from tighter glycemic control and associated reduction in disease burden.

\section{Acknowledgements}

Editorial assistance was provided by Robert Furlong, Sohita Dhillon and Kerry Dechant on behalf of Content Ed Net (Madrid, Spain) with funding from Abbott (São Paulo, Brazil).

\section{Authors' contributions}

All authors contributed extensively to the work presented in this paper. All authors have contributed significantly to the conception, design, or acquisition of data, or analysis and interpretation of data. All authors have participated in drafting, reviewing, and/or revising the manuscript and have approved its submission. All authors read and approved the final manuscript.

\section{Funding}

Editorial assistance was funded by Abbott (São Paulo, Brazil).

\section{Availability of data and materials}

Data sharing is not applicable since it is a review article.

\section{Declarations}

Ethics approval and consent to participate

Not applicable.

\section{Consent for publication}

Authors agree to publish the article in Diabetology \& Metabolic Syndrome.

\section{Competing interests}

Marcio Krakauer has received grants from and participated in Advisory Boards for Abbott, AstraZeneca, Biomm, Boehringer, Lilly, Medtronic, Merck, MSD, Novo Nordisk, P\&G Health, Roche, and Sanofi. Jose Fernando Botero has received grants from and participated in Advisory Boards for Abbott, Novo Nordisk, and Sanofi. Fernando J Lavalle-González has received grants from and participated in Advisory Boards for Abbott, Sanofi, Novo Nordisk, Eli Lilly, Boehringer, MSD, Silanes, Janssen, AstraZeneca, Merck. Adrian Proietti has received conferences fees and participated in Advisory Boards for Abbott and Medtronic. Douglas Eugenio Barbieri is a Regional Medical Director of Abbott Diabetes Care.

\section{Author details}

${ }^{1}$ Department of Technology (Coordinator) SBD-Brazilian Diabetes Society, Science Valley Research Center, Liga de Diabetes, ABC Medical School, Avenida 12 de Outubro 286, Santo André, SP CEP 09030-640, Brazil. ${ }^{2}$ Clínica Integral de Diabetes-CLID, Medellín, Colombia. ${ }^{3}$ Servicio de Endocrinología, Hospital Universitario Dr José e Gonzalez, UANL, Monterrey, México. ${ }^{4}$ Institute of Diabetes and Applied Technology (IDTA), Buenos Aires, Argentina. ${ }^{5}$ Abbott Diabetes Care, Sao Paulo, Brazil.

Received: 28 October 2020 Accepted: 18 March 2021

Published online: 09 April 2021

\section{References}

1. Rydén L, Standl E, Bartnik M, et al. Guidelines on diabetes, pre-diabetes, and cardiovascular diseases. The task force on diabetes and cardiovascular diseases of the European Society of Cardiology (ESC) and of the
European Association for the Study of Diabetes (EASD). Eur Heart J. 2007;28(1):88-136.

2. Polonsky WH, Fisher L, Schikman CH, et al. A structured self-monitoring of blood glucose approach in type 2 diabetes encourages more frequent, intensive, and effective physician interventions: results from the STeP study. Diabetes Technol Ther. 2011;13:797-802.

3. Carlson AL, Mullen DM, Bergenstal RM. Clinical use of continuous glucose monitoring in adults with type 2 diabetes. Diabetes Technol Ther. 2017;19(S2):S4-11.

4. De Ridder F, den Brinker M, De Block C. The road from intermittently scanned glucose monitoring to hybrid closed-loop systems: part A. Keys to success: subject profiles, choice of systems, education. Ther Adv Endocrinol Metab. 2019;10:2042018819865399.

5. Blum A. Freestyle Libre glucose monitoring system. Clin Diabetes. 2018;36(2):203-4.

6. FreeStyle Libre Flash glucose monitoring system. User Manual. May 2019; https://www.diabetescare.abbott/support/manuals/uk.html

7. Ajjan R, Slattery D, Wright E. Continuous glucose monitoring: a brief review for primary care practitioners. Adv Ther. 2019;36(3):579-96.

8. Haak T, Hanaire H, Ajjan R, et al. Flash glucose-sensing technology as a replacement for blood glucose monitoring for the management of insulin treated type 2 diabetes: a multicenter, open-label randomized controlled trial. Diabetes Ther. 2017;8:55-73.

9. HaakT, Hanaire $\mathrm{H}$, Ajjan R, et al. Use of flash glucose-sensing technology for 12 months as a replacement for blood glucose monitoring in insulintreated type 2 diabetes. Diabetes Ther. 2017;8(3):573-86.

10. Ajjan RA, Jackson $\mathrm{N}$, Thomson SA. Reduction in HbA1c using professional flash glucose monitoring in insulin-treated type 2 diabetes patients managed in primary and secondary care settings: A pilot, multicentre, randomised controlled trial. Diab Vasc Dis Res. 2019;16(4):385-95.

11. Yaron M, Roitman E, Aharon-Hananel G, et al. Effect of flash glucose monitoring technology on glycemic control and treatment satisfaction in patients with type 2 diabetes. Diabetes Care. 2019;42(7):1178-84.

12. Kröger J. Fasching, Hanaire H: Three European retrospective real-world chart review studies to determine the effectiveness of flash glucose monitoring on $\mathrm{HbA1C}$ in adults with type 2 diabetes. Diabetes Ther. 2020;11(1):279-91.

13. Wright E, Kerr MSD, Reyes IJ, et al. Use of flash continuous glucose monitoring is associated with $\mathrm{A} 1 \mathrm{C}$ reduction in people with type 2 diabetes treated with basal insulin or noninsulin therapy. Diabetes Spectrum. 2021;16:385-95.

14. Miller $E$, Brandner $L$, Wright $E$. HbA1c reduction after initiation of the FreeStyle Libre ${ }^{\circledR}$ system in type 2 diabetes patients on long-acting insulin or non-insulin therapy. Diabetes. 2020;69(Supplement 1):84-LB.

15. Furler J, O'Neal D, Speight J, et al. Use of professional-mode flash glucose monitoring, at 3-month intervals, in adults with type 2 diabetes in general practice (GP-OSMOTIC): a pragmatic, open-label, 12-month, randomised controlled trial. Lancet Diabetes Endocrinol. 2020;8:17-26.

16. Hermanns N, Ehrmann D, Kulzer B. Professional mode flash glucose monitoring in type 2 diabetes. Lancet Diabetes Endocrinol. 2020;8:2-3.

17. Miller E, Kerr MSD, Roberts GJ, et al. FreeStyle Libre ${ }^{\circledR}$ system use associated with reduction in acute diabetes events and all-cause hospitalizations in patients with type 2 diabetes without bolus insulin. Diabetes. 2020;69(Supplement 1):85-LB.

18. Bergenstal RM, Kerr MSD, Roberts GJ, et al. FreeStyle Libre ${ }^{\circledR}$ system use is associated with reduction in inpatient and outpatient emergency acute diabetes events and all-cause hospitalizations in patients with type 2 diabetes. Diabetes. 2020;69(Supplement 1):69-OR.

19. Roussel R, Guerci B, Vicaut E, et al. Dramatic drop in ketoacidosis rate after FreeStyle Libre ${ }^{\mathrm{TM}}$ system initiation in type 1 and type 2 diabetes in France, especially in people with low self-monitoring of blood glucose (SMBG): a nationwide study. Diabetes. 2020;69(Supplement 1):68-OR.

20. Fokkert M, van Dijk P, Edens M, et al. Improved well-being and decreased disease burden after 1-year use of flash glucose monitoring (FLARE-NL4). BMJ Open Diabetes Res Care. 2019;7(1):e000809.

21. Eeg-Olofsson K, Svensson A-M, Franzén S, et al. Sustainable HbA1c decrease at 12 months for adults with type 1 and type 2 diabetes using the FreeStyle Libre ${ }^{\top M}$ System: a study within the National Diabetes Register in Sweden. Diabetes. 2020;69(Supplement 1):74-LB.

22. Evans $M$, Welsh Z, Ells S, et al. The impact of flash glucose monitoring on glycemic control as measured by HbA1c: A meta-analysis of 
clinical trials and real-world observational studies. Diabetes Ther. 2020;11(1):83-95.

23. Ish-Shalom M, Wainstein J, Raz I, et al. Improvement in glucose control in difficult-to-control patients with diabetes using a novel flash glucose monitoring device. J Diabetes Sci Technol. 2016;10(6):1412-3.

24. Dunn T, Xu Y, Hayter G, et al. Real-world flash glucose monitoring patterns and associations between self-monitoring frequency and glycemic measures: a European analysis of over 60 million glucose tests. Diabetes Res Clin Pract. 2018:137:37-46.

25. Jangam S, Dunn T, Xu Y, et al. Flash glucose monitoring improves glycemia in higher risk patients: a longitudinal, observational study under real-life settings. BMJ Open Diabetes Res Care. 2019;7(1):e000611.
26. Gomez-Peralta F, Dunn T, Landuyt K, et al. Flash glucose monitoring reduces glycemic variability and hypoglycemia: real-world data from Spain. BMJ Open Diabetes Res Care. 2020;8(1):e001052.

27. Calliari LEP, Krakauer M, Vianna AGD, et al. Real-world flash glucose monitoring in Brazil: can sensors make a difference in diabetes management in developing countries? Diabetol Metab Syndr. 2020;12:3.

28. Battelino T, Danne T, Bergenstal RM, et al. Clinical targets for continuous glucose monitoring data interpretation: recommendations from the international consensus on time in range. Diabetes Care. 2019;42(8):1593-603.

\section{Publisher's Note}

Springer Nature remains neutral with regard to jurisdictional claims in published maps and institutional affiliations.
Ready to submit your research? Choose BMC and benefit from:

- fast, convenient online submission

- thorough peer review by experienced researchers in your field

- rapid publication on acceptance

- support for research data, including large and complex data types

- gold Open Access which fosters wider collaboration and increased citations

- maximum visibility for your research: over $100 \mathrm{M}$ website views per year

At BMC, research is always in progress.

Learn more biomedcentral.com/submissions 